\title{
Predictors of postpartum depression in a sample of Egyptian women
}

This article was published in the following Dove Press journal:

Neuropsychiatric Disease and Treatment

21 December 2012

Number of times this article has been viewed

\section{El-Sayed Saleh'}

Wafaa El-Bahei'

Mohamed Adel El-Hadidy'

Abdelhady Zayed ${ }^{2}$

'Psychiatric Department, ${ }^{2}$ Gynecological and Obstetric Department, Mansoura

Faculty of Medicine, Mansoura

University, Mansoura, Egypt
Correspondence: Mohamed Adel El-Hadidy 49 el Thowrah St, Elrefay Tower,

El-Mansoura, Egypt

Tel +20502305959

Email elhadidyy@gmail.com
Introduction: Postpartum depression (PPD) represents a considerable health problem affecting women and their families. The aims of this study were to: (a) compare female patients with PPD to normal controls with regard to some biopsychosocial variables, (b) correlate between the severity of PPD and some clinical and biological variables, and (c) to predict some risk factors for PPD.

Method: Sixty female patients with PPD were compared with 60 healthy postpartum females (control group). Patient and controls were subjected to: (1) a complete psychiatric and obstetric examination, (2) psychometric studies using the Edinburgh Postnatal Depression Scale, Fahmy and El-Sherbini's Social Classification Scale for Egyptian socioeconomic classification and Horowitz et al's Impact of Event Scale, (3) quantities of thyroid hormone (T3), cortisol hormone, and estrogen were assessed.

Results: There were high statistical differences between PPD females and controls as regard psychosocial stressors, level of (estradiol, thyroxin [T3], and cortisol), marital status, residence, parity, method of delivery, complicated puerperium, positive history of premenstrual tension syndrome and baby variables (eg, unwelcomed, with a negative attitude of parents toward the baby, underweight, female, artificially feeding, unhealthy baby). While there were moderate statistical differences in attitude toward spouse and social support and mild statistical difference in socioeconomic status between them. Severity of depression is positively highly correlated with onset of depression, psychosocial stress, levels of T3 and cortisol. However, severity of depression is negatively high when correlated with socioeconomic status. Stepwise linear regression indicated that PPD was significantly predicted by social support, socioeconomic status, feeding of baby, and prior psychiatric problems.

Conclusion: Many factors may lead to development of PPD. These factors include some psychosocial, socioeconomic, obstetric, and hormonal variables. Early detection of these factors could help in prediction of the development of PPD.

Keywords: mood, hormone, delivery, socioeconomic

\section{Introduction}

Clinicians since Hippocrates have noted mood disturbances in new mothers, specifically in the postpartum period. ${ }^{1}$ Postpartum depression (PPD) is now considered a major health concern for women from diverse cultures. ${ }^{2}$ Globally, the prevalence of major PPD ranges from almost $0 \%$ in Singapore to nearly 57\% in Brazil. ${ }^{3}$ However, there are no recent studies that show the overall provincial and national prevalence rates of PPD. ${ }^{4}$

Postpartum depression occurs in women after they have carried a child, usually in the first few postnatal months, and may last up to several months or even a year. ${ }^{5}$ 
Specifically, the onset of PPD begins within 4 weeks and lasts up to 6 months after giving birth. ${ }^{1}$ PPD elicits negative clinical implications for maternal-infant attachment; the mother is withdrawn and disengaged, and there may also be intrusive and hostile mother-infant communication. ${ }^{6-8}$ Research has shown that experiencing symptoms of PPD can have immediate ill effects on children. ${ }^{9}$

Although there is overwhelming evidence that many factors such as marital disharmony, lack of an intimate relationship, previous psychiatric illness, housing problems, and other socioeconomic problems are strongly associated with PPD, ${ }^{10,11}$ a subgroup of women may have a hormonal basis for their depression. ${ }^{10-12}$ Anecdotal support for this has been provided by the finding that the mood of some women with postpartum thyroid dysfunction mimics that of "depressive psychosis."13 The aims of this study were to: (a) compare biopsychosocial variables between female patients with PPD and normal controls; (b) correlate the severity of PPD with clinical and biological variables (specially hormonal variables that may play an important role in the etiology of PPD, eg, estrogen, thyroid, and cortisol); and (c) predict risk factors for development of PPD.

\section{Subjects and methods Study design}

This was a cross-sectional study.

\section{Location and date of the study}

This study was conducted in the in- and outpatient psychiatric departments, and the outpatient clinic of the obstetric and gynecological departments at Mansoura University Hospital, Mansoura city, Dakahlia Governorate, Egypt from July 2006 until January 2007.

\section{Subjects}

During a 6-month period from July 2006 until January 2007, all females delivering in the obstetric department of Mansoura University Hospital were examined by a psychiatrist and obstetrician at least four times: first at 1 week after delivery, then 1, 3, and 12 months after delivery. Patients with PPD were followed more than six times per year. After a senior gynecologist (experience $>12$ years) took the obstetric and menstrual history, all patients were referred to the psychiatric department for further assessment and diagnosis by two senior psychiatrists. Exclusion criteria were: (1) organic mental disorder, substance use disorder, and or mental retardation; (2) associated neurological disease, eg, delirium, dementia, or markedly altered cognitive function; (3) severe language or hearing difficulties; and (4) associated major medical problems. Out of 379 referred females, only $68(17.9 \%)$ were found to meet the diagnostic criteria of the Diagnostic and Statistical Manual of Mental Disorders, fourth edition, text revision (DSM IV-TR) ${ }^{14}$ for major depression with postpartum onset. Only 60 patients of 68 agreed to participate in the study and they constituted the study group. All patients were interviewed by at least two of the authors (psychiatrist with $>15$ years clinical experience) using the Structured Interview for DSM-IV Axis Disorders, Clinician Version (SCID-CV, 10) and diagnosis of PPD was made according to the DSM IV-TR. ${ }^{14}$ The diagnosis was further confirmed by the Edinburgh Postnatal Depression Scale (EPDS), ${ }^{15}$ we used the conventional 13 cut-off score in detecting depression, ie, EPDS $\geq 13$ indicates depressive disorder.

Sixty patients were randomly selected from healthy postpartum females for the control group. Criteria for the control group were that patients should pass the postpartum period without any psychological disturbances and have no past history of psychiatric disorders. All of them were followed up for 1 year after delivery to exclude occurrence of any depressive symptoms during the postpartum period. Out of 311 healthy female subjects screened in the start of the study, only 85 regularly came for follow-up at 1 year postpartum. Nineteen patients refused to participate in the study and six did not fulfill the inclusion criteria so they were excluded. Their mean age was about $28.08 \pm 5.94$ years. The absence of psychiatric disorders was verified by the SCID-CV. All psychological and gynecological date were collected 1 month after delivery. The same exclusion criteria used in selecting the patient group was used for the control group.

\section{Methods}

All puerperal patients and the related control groups were subjected to:

1. Complete psychiatric examination using the semistructured interview of Mansoura University Psychiatric Department with stress upon sociodemographic data and clinical characteristics, which include psychological changes during pregnancy, onset of the disorder after labor, past history of psychiatric illness, etc.

2. Complete obstetric history using the obstetric case sheet of Mansoura University hospital with stress upon parity, pregnancy, labor, puerperium, attitude towards baby, and feeding the baby.

3. Complete menstrual history. 
4. Psychometric studies:

a. The $\operatorname{EPDS}^{15}$ is a 10 -item self-rating questionnaire that, when used after delivery, is highly specific and sensitive in the detection of PPD, as well as it is used as a research tool to measure the severity of the symptoms and not to imply the existence of a well-defined syndrome. ${ }^{16}$ Its reliability and validity has been demonstrated. The Arabic version of the EPDS $^{17}$ has been validated among Egyptian women and its psychometric performance is comparable to the original scale. Scores of 10 or less are considered normal. Scores of 13 or more suggest significant depression.

b. Fahmy and El-Sherbini's Social Classification Scale ${ }^{18}$ for assessing Egyptian socioeconomic status. This score encompasses paternal education and work, family size, housing condition, and per-capita monthly income. A score of 25-30 is considered a high social status, a score of $20-<25$ is considered middle social status, a score of $15-<20$ is considered low social status, and a score of $<15$ is considered very low social status.

c. The Impact of Event Scale was developed by Horowitz et $\mathrm{al}^{19}$ to assess the presumptive stress score. Its scores can be classified into no life crises (0-149), mild-to-moderate (150-299), and major life crises $(>300)$.

5. Hormonal assay: thyroid hormone (T3), cortisol, and estrogen were assessed for all control group and patients at 1 week after delivery (which is the expected time for all hormones to return to a normal level).

\section{Ethical consideration}

The current study was approved by the Mansoura University Faculty of Medicine Ethical Committee. All patients and controls gave informed consent in accordance with the Helsinki II Declaration after the purpose of the study and the protocol had been explained to them, and before any intervention was performed.

\section{Statistical analysis}

Data entry and analysis were made by SPSS software (version 19; IBM, Armonk, NY). Parametric data were summarized as means and standard deviations, and the association differences were compared using $t$-tests. Nonparametric data were described as number and percentage, and the associated differences were compared using chi-square test. The main findings were presented as proportions with $95 \%$ confidence intervals. Correlation was tested by Pearson product-moment correlation coefficient equation and stepwise linear regression model was applied to predict PPD risk factors.

\section{Results}

The prevalence of PPD was $17.9 \%$. Of 60 patients with PPD, the onset of PPD was as follows: In the first week after labor, $10.6 \%$ of patients started to develop PPD; from the second week to 1 month postlabor, $19.4 \%$ of patients started to develop PPD; $42 \%$ of patients showed PPD in the second month, $26 \%$ in the third to sixth month, and $2 \%$ of them in more than 6 months. The mean age of women with PPD was $28.97 \pm 5.08$ years. Nine (15\%) PPD women had psychiatric problems prior onset of PPD, eg, postpartum blues, $25(41.7 \%)$ were previously hospitalized due to their disorder, and $41(68.3 \%)$ had a past history of similar conditions whether puerperal, nonpuerperal, and with pregnancy without delivery.

The present study found that there was a mild statistical difference in socioeconomic status between PPD and control groups $(t=-2.063 ; P<0.01)$, while there was a high statistical difference in psychosocial stressors and the level of hormones (estradiol, thyroxin [T3], and cortisol) between groups (Table 1).

High statistical differences were found in marital status, residence, parity, method of delivery, complicated puerperium, positive history of premenstrual tension syndrome (PMTS) between the PPD and control groups (Table 2). There were moderate statistical differences in attitude toward spouse and social support. However, there was no significant difference whether the pregnancy was planned or unwanted between both groups.

Having an unwelcome infant, with a negative parental attitude toward the baby was more prevalent in the PPD group than the control group with a high statistical difference. Having an underweight female infant, artificially feeding, and unhealthy baby was more prevalent in the PPD group than the control group with high statistical difference (Table 3 ).

Table 4 shows the correlation between the severity of PPD using EPDS and some clinical and biological variables in PPD patients. Severity of depression was positively highly correlated with onset of depression, psychosocial stress, levels of T3 and cortisol. On the other hand, severity of depression was negatively high correlated with socioeconomic status. There was no significant correlation in age and level of estradiol. Stepwise linear regression indicated that PPD was significantly predicted by social support, socioeconomic status, feeding baby, and prior psychiatric problems (Table 5). 
Table I Clinical data of both postpartum depression and control groups

\begin{tabular}{|c|c|c|c|c|c|}
\hline & \multirow{2}{*}{\multicolumn{2}{|c|}{$\begin{array}{l}\text { Postpartum depression group } \\
\text { No }=60\end{array}$}} & \multirow{2}{*}{\multicolumn{2}{|c|}{$\begin{array}{l}\text { Control group } \\
\text { No }=60\end{array}$}} & \multirow[t]{3}{*}{$\boldsymbol{t}$} \\
\hline & & & & & \\
\hline & Mean & \pm SD & Mean & $\pm \mathbf{S D}$ & \\
\hline Age & 28.97 & 5.08 & 28.08 & 5.94 & 1.38 \\
\hline Age of menarche & 12.15 & $\mathrm{I} .44$ & 12.80 & 1.77 & -1.96 \\
\hline Socioeconomic status ${ }^{a}$ & 17.93 & 4.56 & 24.98 & 26.57 & $-2.06 *$ \\
\hline Presence of postpartum depression ${ }^{b}$ & 11.57 & 4.99 & 5.97 & 2.78 & $8.16^{* * *}$ \\
\hline Psychosocial stressors $^{c}$ & 207.67 & 62.05 & 45.07 & 19.32 & $13.38 * * *$ \\
\hline Level of estradiol & 20.63 & 60.00 & 58.21 & 77.41 & $-6.07 * * *$ \\
\hline Level of thyroxin (T3) & 1.07 & 0.43 & 1.39 & 0.36 & $-7.57 * * *$ \\
\hline Level of cortical & 8.32 & 4.27 & 11.92 & 4.91 & $-11.16 * * *$ \\
\hline
\end{tabular}

Notes: aUsing Fahmy and El-Sherbini's Social Classification Scale; 'busing Edinburgh Postnatal Depression Scale; 'using Horowitz's Impact of Event Scale; *P < 0.05; ****P $<0.001$.

Abbreviation: SD, standard deviation.

Table 2 Sociodemographic and clinical data of both postpartum depression and control groups

\begin{tabular}{|c|c|c|c|c|c|}
\hline & \multicolumn{2}{|c|}{ Postpartum depression group } & \multicolumn{2}{|c|}{ Control group } & \multirow[t]{2}{*}{$\chi^{2}$} \\
\hline & $\mathbf{n}$ & $\%$ & $\mathbf{n}$ & $\%$ & \\
\hline \multicolumn{6}{|l|}{ Marital status } \\
\hline Married monogamy & 44 & $73.3 \%$ & 47 & $78.3 \%$ & $84.84 * * *$ \\
\hline Married polygamy & 7 & $11.7 \%$ & 6 & $10 \%$ & \\
\hline Separated & 6 & $10 \%$ & 4 & $6.7 \%$ & \\
\hline Widowed & 3 & $5 \%$ & 3 & $5 \%$ & \\
\hline \multicolumn{6}{|l|}{ Residence } \\
\hline Urban & 22 & $36.7 \%$ & 25 & $41.7 \%$ & $48.632 * * *$ \\
\hline Rural & 38 & $63.3 \%$ & 35 & $58.3 \%$ & \\
\hline \multicolumn{6}{|l|}{ Parity } \\
\hline Primipara & 16 & $26.7 \%$ & 6 & $10 \%$ & $80.93 * * *$ \\
\hline Multipara & 44 & $63.3 \%$ & 54 & $90 \%$ & \\
\hline $2 n d-3 r d$ & 26 & $43.3 \%$ & 23 & $38.3 \%$ & \\
\hline 4th-6th & 15 & $25 \%$ & 29 & $48.3 \%$ & \\
\hline$>6$ th & 3 & $5 \%$ & 2 & $3.3 \%$ & \\
\hline \multicolumn{6}{|c|}{ Attitude towards pregnancy } \\
\hline Wanted & 42 & $70 \%$ & 57 & $95 \%$ & 1.35 \\
\hline Unwanted & 18 & $30 \%$ & 3 & $5 \%$ & \\
\hline \multicolumn{6}{|l|}{ Planning of pregnancy } \\
\hline Planned & 42 & $70 \%$ & 55 & $91.7 \%$ & 0.26 \\
\hline Unplanned & 18 & $30 \%$ & 5 & $8.3 \%$ & \\
\hline \multicolumn{6}{|l|}{ Method of delivery } \\
\hline Unassisted & 27 & $45 \%$ & 48 & $80 \%$ & $41.25^{* * *}$ \\
\hline Forceps-assisted & 17 & $28.3 \%$ & 6 & $10 \%$ & \\
\hline Caesarean & 16 & $26.7 \%$ & 6 & $10 \%$ & \\
\hline \multicolumn{6}{|l|}{ Puerperium } \\
\hline Normal & 26 & $43.3 \%$ & 48 & $80 \%$ & $11.47^{* * *}$ \\
\hline Complicated & 34 & $56.7 \%$ & 12 & $20 \%$ & \\
\hline \multicolumn{6}{|l|}{ Attitude toward spouse } \\
\hline Positive & 23 & $38.3 \%$ & 50 & 10 & $7.45 * *$ \\
\hline Negative & 37 & $61.7 \%$ & $83.3 \%$ & $16.7 \%$ & \\
\hline \multicolumn{6}{|l|}{ Social support } \\
\hline Adequate & 19 & $31.7 \%$ & 46 & $76.7 \%$ & $8.46 * *$ \\
\hline Inadequate & 41 & $68.3 \%$ & 14 & $23.3 \%$ & \\
\hline \multicolumn{6}{|l|}{ History of PMTS } \\
\hline Yes & 39 & $65 \%$ & 15 & $25 \%$ & $10.76 * * *$ \\
\hline No & 21 & $35 \%$ & 45 & $75 \%$ & \\
\hline
\end{tabular}

Notes: $* * p<0.01$; $* * * p<0.001$.

Abbreviation: PMTS, premenstrual tension syndrome. 
Table 3 Factors in newborn infant in both postpartum depression and control groups

\begin{tabular}{|c|c|c|c|c|c|}
\hline & \multicolumn{2}{|c|}{ Postpartum depression group } & \multicolumn{2}{|c|}{ Control group } & \multirow[t]{2}{*}{$\chi^{2}$} \\
\hline & $\mathbf{n}$ & $\%$ & $\mathbf{n}$ & $\%$ & \\
\hline \multicolumn{6}{|l|}{ Emotional reaction toward baby } \\
\hline Welcomed & 25 & $41.7 \%$ & 37 & $61.7 \%$ & \multirow[t]{2}{*}{$26.64 *$} \\
\hline Unwelcomed & 35 & $58.3 \%$ & 23 & $38.3 \%$ & \\
\hline \multicolumn{6}{|l|}{ Attitude toward baby } \\
\hline Positive & 25 & $41.7 \%$ & 48 & $80 \%$ & \multirow[t]{2}{*}{$10.71 *$} \\
\hline Negative & 35 & $58.3 \%$ & 12 & $20 \%$ & \\
\hline \multicolumn{6}{|l|}{ Birth weight } \\
\hline Average & 39 & $65 \%$ & 49 & $81.7 \%$ & \multirow[t]{2}{*}{$25.01 *$} \\
\hline Underweight & 21 & $35 \%$ & II & $18.3 \%$ & \\
\hline \multicolumn{6}{|l|}{ Sex of baby } \\
\hline Male & 23 & $38.3 \%$ & 35 & $58.3 \%$ & \multirow[t]{2}{*}{$26.64 *$} \\
\hline Female & 37 & $61.7 \%$ & 25 & $41.7 \%$ & \\
\hline \multicolumn{6}{|l|}{ Feeding baby } \\
\hline Breast & 23 & $38.3 \%$ & 32 & $53.3 \%$ & \multirow[t]{2}{*}{$32.63 *$} \\
\hline Artificial & 37 & $61.7 \%$ & 28 & $46.7 \%$ & \\
\hline \multicolumn{6}{|l|}{ Baby health } \\
\hline Normal & 42 & $70 \%$ & 45 & $75 \%$ & \multirow[t]{7}{*}{$194.00 *$} \\
\hline Premature & 4 & $6.7 \%$ & 1 & $1.7 \%$ & \\
\hline Stillbirth & 2 & $3.3 \%$ & 4 & $6.7 \%$ & \\
\hline Congenitally abnormal & 1 & $1.7 \%$ & 2 & $3.3 \%$ & \\
\hline Intrauterine fetal death & 1 & $1.7 \%$ & 2 & $3.3 \%$ & \\
\hline Precious baby & 6 & $10 \%$ & 2 & $3.3 \%$ & \\
\hline $\begin{array}{l}\text { Complication, eg, jaundice, } \\
\text { sticky eye, cord around the neck }\end{array}$ & 4 & $6.7 \%$ & 4 & $6.7 \%$ & \\
\hline
\end{tabular}

Note: $* p<0.001$.

\section{Discussion}

In this study, the prevalence of PPD was $17.9 \%$, which is similar to previous results in developed countries ${ }^{20}$ and developing countries including Sudan ${ }^{21}$ and Upper Egypt. ${ }^{22}$ There was significant statistical difference in EPDS score between PPD patients and the control group $(t=8.16 ; P<0.001)$. These results were similar to the results found by Hannah et $\mathrm{al}^{16}$ and Warner et al..$^{23}$

Most PPD symptoms in this study began within the second and third months and persisted for $>6$ months. This finding is contrary to other western studies such as Hannah

Table 4 Correlation between severity of postpartum depression using EPNDQS and clinicobiological variables of postpartum depression patients

\begin{tabular}{llll}
\hline Clinical variables & Mean & Standard deviation & $\mathbf{r}$ \\
\hline Age & 28.97 & 5.09 & 0.18 \\
Onset of depression & 3.18 & 1.63 & $0.83^{*}$ \\
Age of menarche & 12.15 & 1.44 & 0.071 \\
Socioeconomic status & 17.93 & 4.56 & $-0.75^{*}$ \\
Psychosocial stress & 207.67 & 62.05 & $0.59^{*}$ \\
Level of estradiol & 20.63 & 60.00 & 0.25 \\
Level of thyroxin (T3) & 1.07 & 0.43 & $0.64^{*}$ \\
Level of cortisol & 8.32 & 4.27 & $0.66^{*}$ \\
\hline
\end{tabular}

Note: *Pearson's correlation coefficient $(r)$, two-tailed $P<0.00$ I. et $\mathrm{a}^{16}$ who found that depression in $42 \%$ of a PPD sample began in the first week postpartum. This difference may be possibly because a substantial segment of the rural populations of Egypt believe that the puerperium is a period of "uncleanliness," which imposes taboos on women such as cooking, washing, and cohabiting with her husband. Rest and relative seclusion are also imposed. ${ }^{24}$ Even in Egyptian urban areas, rituals allow for 40-day rest periods for the mother after the birth of a baby. During that period, the focus is on allowing the mother time to rest, eat, and sleep. Female relatives come to help with housekeeping and care for the new baby. Thus, social support, education, childcare services, and social recognition of the new motherhood status are ensured. This social fabric may delay the onset of major depression and ameliorate mood disturbances to a subthreshold level. After the first postnatal month, as families and relatives gradually decrease their intense emotional and practical support, depression may ultimately set in. As in Egypt, Chinese women have a relatively lower rate of depression in early puerperium. The first month of puerperium in Chinese society is demarcated by rituals. According to traditional beliefs, a recently delivered woman is in a Yin state (with depletion of vitality) and she is encouraged to recover her health by resting in bed and taking tonics. In the first postnatal month, she is 
Table 5 Risk factors of postpartum depression using long linear regression analysis

\begin{tabular}{|c|c|c|c|c|}
\hline \multirow[t]{2}{*}{ Model } & \multicolumn{2}{|c|}{ Unstandardized coefficients } & \multirow{2}{*}{$\begin{array}{l}\text { Standardized coefficients } \\
\text { Beta }\end{array}$} & \multirow[t]{2}{*}{$t$} \\
\hline & B & Standard error & & \\
\hline I. (Constant) & -3.70 & 1.27 & & $-2.91 * *$ \\
\hline Social support & 9.07 & 0.73 & 0.85 & $12.47 * * *$ \\
\hline 2. (Constant) & 7.16 & 2.74 & & $2.6 I^{* *}$ \\
\hline Social support & 6.65 & 0.85 & 0.63 & $7.85^{* * *}$ \\
\hline Socioeconomic status & -0.38 & 0.09 & -0.35 & $-4.34 * * *$ \\
\hline 3. (Constant) & 5.90 & 2.59 & & $2.27^{*}$ \\
\hline Social support & 3.72 & 1.24 & 0.35 & $2.99 * *$ \\
\hline Socioeconomic status & -0.35 & 0.08 & -0.32 & $-4.2 I^{* * *}$ \\
\hline Feeding baby & 3.48 & 1.14 & 0.34 & $3.06 * *$ \\
\hline 4. (Constant) & 0.50 & 3.52 & & 0.15 \\
\hline Social support & 3.10 & 1.24 & 0.29 & $2.47^{*}$ \\
\hline Socioeconomic status & -0.25 & 0.09 & -0.23 & $-2.69 * *$ \\
\hline Feeding baby & 3.65 & 1.10 & 0.36 & $3.3 I^{*}$ \\
\hline Prior psychiatric problem & 2.40 & 1.10 & 0.17 & $2.19 *$ \\
\hline
\end{tabular}

Notes: $* p<0.05 ; * * p<0.01$; $* * *<<0.001$.

spared from all household chores and is attended by a female relative, usually the mother or mother-in-law..$^{25}$ In contrast, Western women usually go home a day after delivery and often without an extended family or neighbors to help with infant care. In that isolated environment, the woman does not receive the supportive therapeutic factors that would help mitigate the development or the exacerbation of a spectrum of nonpsychotic depressions.

\section{Demographic data}

The current study observed that the postpartum psychiatric disorders were $28.97 \pm 5.08$ years, this finding was consistent with Cutrona ${ }^{26}$ who found that the mean age for puerperal depressives was 27 years. This may be attributed to younger age of marriage in Egyptian society especially in rural areas. Wolff $\mathrm{et} \mathrm{l}^{27}$ considered young age as a risk factor for puerperal depression, however, O'Hara and $\mathrm{Swain}^{28}$ and $\mathrm{Beck}^{29}$ didn't show the same results.

In this study, rural residences were more prevalent in the PPD group than in the control group with a highly statistically significant difference $\left(\chi^{2}=48.632 ; P<0.001\right)$. However, Peter et $\mathrm{al}^{30}$ found no association between the demographic factors and the psychiatric morbidity during puerperium. This may be explained by the fact that most of the Egyptian population comes from rural areas where females married at an earlier age, while being immature, less educated, and less employed, with a greater demand for housekeeping, which may lead to more social and family troubles since the wife is still living with her mother-in-law. This may be considered as a stressful factor for development of PPD in vulnerable individuals. Moreover, in this study, lower socioeconomic status was more prevalent among the PPD group than in the control group $(t=-2.06 ; P<0.05)$. Socioeconomic status was significantly correlated with PPD $(r=-0.758$; $P<0.001)$ and can be considered as predictor of PPD $(\mathrm{B}=-0.225 ; t=-2.694 ; P<0.01)$. This was consistent with Hafiz $^{31}$ and Chandra ${ }^{32}$ who highlighted the importance of social factors, especially poverty, as a risk factor for antenatal depression and PPD.

Several investigators have drawn attention to links between the occurrence and severity of PPD and the amount and quality of support that is provided by husbands and by relatives. ${ }^{33}$ Kumar and Robson ${ }^{34}$ emphasized the importance of the relationship with the husband and its role in postpartum disorders, especially depression. Our study revealed that marital disruption, whether emotionally (ie, a negative attitude toward spouse) or sexually (ie, married polygamy, separated, and widowed), were more prevalent in puerperal patients than $\operatorname{control}\left(\chi^{2}=84.835\right.$ and 7.459, respectively; $\left.P<0.001\right)$. This point also was supported by Okasha et al. ${ }^{35}$ To reinforce the idea that feelings of being unloved by the husband, being separated, or any other marital problems, were found to be associated with PPD in vulnerable females, a western study enumerates polygamy, marital problems, and divorce as risk factors for postpartum psychiatric disorders. ${ }^{36}$

Oyewumi et al ${ }^{37}$ defined social support as the availability of assistance in daily living from one or any combination of family, relatives, friends or community agencies. Our results revealed that social support provided by the spouse and/or relatives to women experiencing PPD was deficient and inadequate with statistical significant difference between patients and controls $\left(\chi^{2}=8.462 ; P<0.01\right)$ and can be considered 
as predictor of PPD $(\mathrm{B}=0.288 ; t=2.466 ; P<0.05)$. That finding was in agreement with several studies. Two studies stated that lack of social support becomes more important as people migrate to big cities with disappearance of the extended family and the rituals that give help and social support to postpartum women after delivery. ${ }^{38,39}$

PPD was found to be associated with an increased number of stressful life events during the preceding 12 months. ${ }^{40}$ In our study, psychosocial stressors were found to be significantly higher in the PPD group than control group $(t=13.38$; $P<0.001)$ and positively highly correlated with the severity of PPD ( $\mathrm{r}=0.588 ; P<0.001)$. Stressful life events might be associated with depressive episodes in two ways. First, life stresses might have a causal relationship to a depressive episode and once a depression-related life event occurs, it might then cause negative feelings in the patient with increased feelings of hopelessness with deepening of the depressive episode.$^{41}$ Finally, it was predicted that depressed subjects would experience more stressful life events since the beginning of pregnancy and since delivery compared to nondepressed subjects. ${ }^{16}$

In this study, 15\% of PPD women had psychiatric problems prior to onset of PPD, eg, anxiety, postpartum blues, etc. Psychiatric problems prior to onset of PPD were considered as a predictor for $\mathrm{PPD}(\mathrm{B}=0.173 ; t=2.190 ; P<0.05)$. This is consistent with $\mathrm{O}^{\prime} \mathrm{Hara}$ et $\mathrm{al}^{33}$ who described the depressive symptoms during pregnancy as the best predictor of PPD. Dean and Kendell ${ }^{42}$ found most of the PPD patients whose symptoms began during pregnancy had an exacerbation of symptoms in the 2 weeks following delivery.

In our study, more than two thirds of PPD patients had a past history of similar conditions. This is concordant with many previous studies. ${ }^{43-45}$ However, other studies ${ }^{16,37}$ found no association between past psychiatric history and PPD.

\section{Obstetric variables}

Some earlier studies didn't find any association between parity and PPD. ${ }^{15,34}$ Our parity results contradict previously mentioned studies, ie, primipara represented only one fourth of PPD females. Moreover, in a Saudi Arabian study, Shoeb and $\mathrm{Hassan}^{46}$ found that multigravida admissions to psychiatric hospitals occurred more readily than primigravida admissions. Our finding and that of Shoeb and Hassan ${ }^{46}$ could be explained by the characteristic social norms of the locality especially in rural Egyptian areas (63.3\% of our PPD females came from rural areas). As a newly married woman is likely to spend the first few years of her marriage with the extended family (her parents or her husband's parents), where there is considerable support, she is also likely to be treated in a private hospital. The couples are likely to live apart from the extended family after a few years of marriage when they have children and are becoming more independent economically. Hence, we suspect that multigravida patients have less support during pregnancy and after delivery than primigravida patients, and this may account for the increased number of multigravida patients in our sample.

Unwanted and/or unplanned pregnancy may result in an ambivalent feeling towards the child even before birth or a lack of commitment to the infant, both of which have been associated with depression. Difficulties in adjusting to parenthood and feelings of entrapment are prominent in PPD and are likely to be greater if the baby is unplanned. ${ }^{34}$ These findings were consistent with this study where $30 \%$ of PPD females reported unwanted and/or unplanned pregnancy compared with the control group ( $5 \%$ and $8.3 \%$, respectively), in spite of an absence of statistical difference in unwanted and unplanned pregnancy between groups. Kubicka et al ${ }^{47}$ and Wolff et al ${ }^{27}$ found that mothers with unwanted pregnancies were more frequently emotionally disturbed than the female control group who accepted their pregnancy. Some researchers stated that there are established antenatal risk factors for PPD such as obstetric and pregnancy complications and depression or anxiety during pregnancy while our study didn't show pregnancy complication, length of gestation, or interval between pregnancies to play a significant role in puerperal illness. ${ }^{48,49}$

The current study revealed a significant difference in difficult labor and/or complicated puerperium between PPD patients and the control group. These findings were in agreement with many studies as operative interventions leave a mother susceptible to grief, post-traumatic distress, diminution in self-esteem and depression. ${ }^{16,50-52}$ In contrast, some researchers didn't find a significant correlation between PPD and difficult labor. ${ }^{53}$

\section{Infant variables}

In this study, infants were unwelcome for PPD patients, who had a negative reaction towards them, which ranged from a nonaffectionate attitude to attempted infanticide. Many authors support this finding, eg, Curran et a ${ }^{54}$ reported that not every baby is wholeheartedly wanted and there is quite often underlying hostility and jealousy toward him or her. Gelder et a $l^{55}$ explained that severely depressed patients may have delusional ideas that the child is malformed or otherwise imperfect. These false ideas may lead to attempts to kill the child to spare it from future suffering. 
Studies conducted within Western societies have found no association between the sex of the child and PPD. However, recent studies from India suggested that spousal disappointment with the sex of the baby, specifically if the baby is a girl, is significantly associated with developing PPD. ${ }^{56,57} \mathrm{In}$ the current study, PPD patients gave birth to more female babies with high significant difference between them and controls $\left(\chi^{2}=26.641 ; P<0.001\right)$. In Egyptian culture, the social belief is that males are superior and have more advantages than females. In some cultures, especially in rural areas, delivery of a female baby may bring criticism of the mother from the father and his family and the relationship may end in divorce. Therefore, the parent's reaction to the sex of the baby may be a potential risk factor for PPD within certain cultural groups.

In this study, infants of PPD patients were more liable to be underweight than infants of the control group. This is inconsistent with Hannah et al's ${ }^{16}$ findings; underweight babies may be prone to impaired health, which in turn leads to more stress on their mothers. In the current study, 18 of our puerperal patients had problems with their baby (premature baby, 6.7\%; stillbirth, 3.3\%; congenitally abnormal, 1.7\%; intrauterine fetal death, $1.7 \%$; baby complication, eg, cord around the neck, 6.7\%) with highly significant differences between groups. Our results coincide with Paradiso et al ${ }^{58}$ who reported that women were scared by giving birth to a deformed child.

In the current study, PPD patients fed their babes artificially more than control patients. Moreover, bottlefeeding was found to be a predictor of PPD. This finding could be explained by the failure of the depressed mother to breastfeed their babies. Similarly, several studies found that bottle feeding was a significant risk factor for PPD. ${ }^{16,59-61}$ While breast feeding may enhance self-esteem and so make depression less likely ${ }^{16}$ and some claim that breastfeeding can reduce the incidence of PPD by as much as $50 \% .^{62}$

\section{Biological data (hormonal profile)}

Changes in hormone levels are informally believed to lead to PPD, but, to date, there have not been any conclusive research linking hormonal changes as a causal factor in the onset of PPD. Data does exist implicating changes in progesterone, estradiol, and prolactin levels, as well as changes in thyroid functioning and adrenal steroid level, in the development of depression. ${ }^{63-65}$

This study revealed that there is a greater postpartum drop in serum estradiol, T3, and morning cortisol levels in the PPD group compared with the control group. Positive correlation with the severity of depression was found with morning cortisol level and T3, but not with serum estradiol.

Since hormonal levels immediately change following pregnancy, these changes may account for some of the immediate mood fluctuations. However, the development of significant postpartum symptoms appears to be related to additional necessary factors such as sensitivity to mooddestabilizing effects of gonadal steroids ${ }^{63}$ or the interaction of hormonal factors and external stressors. ${ }^{64}$ As noted in a review by Gjerdingen and Yawn, ${ }^{66}$ research examining hormonal factors has not been conclusive. Additional systematic research is necessary to assess the etiological and possible interactive role of hormonal factors in the development of PPD. Nevertheless, treating PPD with hormonal therapies has had some demonstrated support. The findings in the current study were in agreement with Ahokas et a ${ }^{67}$ where they found that estrogen and progesterone sharply drop to prepregnant levels by the third postpartum day. The relationship between postpartum thyroid dysfunction and PPD may support a "hormonal" etiology for a small number of cases of PPD. In one study, the incidence of transient postpartum thyroid dysfunction was $7 \%$ and the incidence of either major or minor depression was $21 \%$ according to research diagnostic criteria. ${ }^{68}$

\section{Limitation of the study}

This is a cross-sectional study and hence it is not possible to reach conclusions regarding causal links. It is a longitudinal study including serial hormonal levels before delivery and several times in different periods after labor. Because it was impossible to study every reported risk factor, only the consistently reported ones in the literature were evaluated (psychosocial, clinical, and hormonal variables). This study focuses on outlining the obstetric, psychological, and social factors predicting causation of PPD, and on exploration of the role of the three commonly studied hormones in relation to PPD and identification of risk factors that have been reported to be associated with the PPD. Further studies exploring more factors would be beneficial.

\section{Conclusion and recommendation}

Many factors may lead to development of PPD, including psychosocial, socioeconomic, obstetric, and hormonal factors. Early detection of these factors may help for early intervention and management.

A psychiatrist and a social worker must attend a postnatal care unit to advise mothers who may be at risk to develop not only PPD, but also other psychiatric disorders. 
Recording a psychiatric history for pregnant women in antenatal care units are important to know the mothers at risk for developing puerperal psychiatric disorders as they need extra support. Screening for PPD should become routine by using the EPDS 5 days postpartum for early detection and management.

\section{Disclosure}

There is no conflict of interest for all authors and the study was not supported by any financial support or relationships that may pose conflict of interest from any institute or company.

\section{References}

1. Miller LJ. Postpartum depression. JAMA. 2002;287:762-765.

2. Dennis CE, Stewart DE. Treatment of postpartum depression, part 1: a critical review of biological interventions. $J$ Clin Psychiatry. 2004;65:1242-1251.

3. Halbreich U, Karkun S. Cross-cultural and social diversity of prevalence of postpartum depression and depressive symptoms. J Affect Disord. 2006;91:97-111.

4. Andrea L, Jennifer LK, Hala T. Prevalence and characteristics of postpartum depression symptomatology among Canadian women: a cross-sectional study. BMC Public Health. 2011;11:302.

5. Canadian Mental Health Association. Postpartum depression. Available from: http://www.cmha.ca/mental_health/postpartum-depression/ Accessed on June 13, 2012.

6. Barnes DL. Postpartum depression: Its impact on couples and marital satisfaction. Journal of Systemic Therapies. 2006;25:25-42.

7. Dennis C, McQueen K. The relationship between infant-feeding outcomes and postpartum depression: a qualitative systematic review. Pediatrics. 2009;123:736-751.

8. Mancini F, Carlson C, Albers L. Use of the Postpartum Depression Screening Scale in a collaborative obstetric practice. J Midwifery Womens Health. 2007;52:429-434.

9. Kavanaugh M, Halterman J, Montes G, Epstein M, Hightower AD, Weitzman M. Maternal depressive symptoms are adversely associated with prevention practices and parenting behaviors for preschool children. Ambul Pediatr. 2006;6:32-37.

10. Paykel ES, Emms EM, Fletcher J, Rassaby ES. Life events and social support in puerperal depression. Br J Psychiatry. 1980;136:339-346.

11. Watson JP, Elliott SA, Rugg AJ, Brough DI. Psychiatric disorder in pregnancy and the first postnatal year. Br J Psychiatry. 1984;144: 453-462.

12. Harris B, Johns S, Fung H, et al. The hormonal environment of post natal depression. Br J Psychiatry. 1989;154:660-667.

13. Amino N, Mori H, Iwatani Y, et al. High prevalence of transient post-partum thyrotoxicosis and hypothyroidism. $N$ Engl J Med. 1982;306:849-852.

14. American Psychiatric Association. Diagnostic and Statistical Manual of Mental Disorders. 4th ed, text rev. Washington, DC: American Psychiatric Association; 2000.

15. Cox JL, Holden JM, Sagovsky R. Detection of postnatal depression. Development of the 10-item Edinburgh Postnatal Depression Scale. Br J Psychiatry. 1987;150:782-786.

16. Hannah P, Adams D, Lee A, Glover V, Sandler M. Links between early post-partum mood and post-natal depression. Br J Psychiatry. 1992;160:777-780.

17. Ghubash R, Abou-Saleh MT, Daradkeh TK. The validity of the Arabic Edinburgh Postnatal Depression Scale. Psychiatr Epidemiol. 1997;32:474-476.

18. Fahmy SI, El-Sherbini AF. Determining simple parameters for social classification for health research. The Bulletin of the High Institute of Public Health. 1988;13:95-108.
19. Horowitz M, Schaefer C, Conney P. Life event questionnaires for measuring presumptive stress. Psychosom Med. 1977;39:413-431.

20. Lanes A, Kuk JL, Tamim H. Prevalence and characteristics of postpartum depression symptomatology among Canadian women: a crosssectional study. BMC Public Health. 2011;11:302.

21. Sati HA. Prevalence of postnatal depression among Sudanese women and the associated risk factors. The Sudanese Journal Of Psychiatry. 2011;1:153-165.

22. Mohamed NA, Mahmoud GA, Said NA, Abdelhafez HA, Maklof A MA. Postpartum depression: prevalence and predictors among women at El Eman's specialized hospital. J Am Sci. 2011;7(12):1-4.

23. Warner R, Appleby L, Whitton A, Faragher B. Demographic and obstetric risk factors for postnatal psychiatric morbidity. $\mathrm{Br} J$ Psychiatry. 1996;168:607-611.

24. Shaheen O. The behavioural sciences. Medical anthropology. Lecture notes (Arabic); Cairo, Egypt: Cairo University; 1983.

25. Lee DS, Yip KS, Chiu FK, et al. Detecting post natal depression in Chinese women. Br J Psychiatry. 1998;172:433-437.

26. Cutrona CE. Causal attribution and perinatal depression. $J$ Abnorm Psychol. 1983;91:457-461.

27. Wolff A, De Andraca I, Lozoff B. Maternal depression in three Latin American samples. Soc Psychiatry Psychiatr Epidemiol. 2002;37: 169-176.

28. O'Hara MW, Swain AM. Rates and risk of postpartum depression-a meta-analysis. Int Rev Psychiatry. 1996;8:37-54.

29. Beck CT. Predictors of postpartum depression: an update. Nurs Res. 2001;50:275-285.

30. Peter J, Tomlinson M, Swartz L, et al. Postpartum depression and the mother infant relationship in a South African peri-urban. $B r J$ Psychiatry. 1999;175:554-558.

31. Hafiz W. Assessment of psychological status of Egyptian women during pregnancy. MSc thesis. Cairo, Egypt: Cairo University; 1997.

32. Chandra PS. Post partum psychiatric care in India. World Psychiatry. 2004;3:90-100.

33. O'Hara MW, Schlechte JA, Lewis DA, et al. Prospective study of postpartum blues. Arch Gen Psychiatry. 1991;48:801-806.

34. Kumar R, Robson K. A prospective study of emotional disorders in childbearing women. Br J Psychiatry. 1984;166:191-195.

35. Okasha A, Khalil AH, Younis N, Youssef I, Demerdask A. The postpartum psychiatric disorders: A descriptive and epidemiological study. Egypt J Psychiatry. 1987;10:161-174.

36. O'Hara MW, Swain AM. Rates and risk of postpartum depression a meta analysis. Int Rev Psychiatry. 1996;8:37-54.

37. Oyewumi LK, Odejide MD, Kazzrian SJ. Psychiatric emergency services in a Canadian city. Can J Psychiatry. 1992;37:91-99.

38. O'Hara MW. Social support, life events and depression during pregnancy and puerperium. Arch Gen Psychiatry. 1986;43: $569-573$.

39. Rondon MB. Childbirth is not only complex: it may be also dangerous. World Psychiatry. 2004;3:98-99.

40. Oates M. The development of an integrated community service for severe postnatal mental illness. In: Kumar S, Brochington IF, editors. Motherhood and Mental Illness 2: Causes and Consequences. London, UK: Wright; 1988:133-158.

41. Abou El-Hoda MF. A study of factors affecting recovery from major depressive episodes and future relapses. MD Thesis. Mansoura, Egypt, Mansoura University Press. 1994.

42. Dean C, Kendell ER. The symptomatology of puerperal illness. $\mathrm{Br} J$ Psychiatry. 1981;139:128-133.

43. Watson JP, Elliott SA, Rugg AJ, et al. Psychiatric disorder in pregnancy and the first postnatal year. Br J Psychiatry. 1984;144:35-47.

44. Paykel EE, Emms EM, Fletcher J, et al. Life events and social support in puerperal depression. Br J Psychiatry. 1980;136:339-346.

45. O'Hara MW, Swain AM. Rates and risk of postpartum depression a meta-analysis. Int Rev Psychiatry. 1996;8:37-54.

46. Shoeb IH, Hassan GA. Post-partum psychosis in the Assir Region of Saudi Arabia. Br J Psychiatry. 1990;157:424-430. 
47. Kubicka L, Matejcek Z, David HP, Dytrych WB, Roth Z. Children from unwanted pregnancy in Prague; Czech Republic revisited at age thirty. Acta Psychiatr Scand. 1995;91:361-369.

48. Beck CT, Gable RK. Postpartum Depression Screening Scale Manual. Los Angeles, CA: Western Psychological Services; 2002.

49. Kendell RE, Chalmers JC, Platz C. Epidemiology of puerperal psychoses. Br J Psychiatry. 1987;150:662-673.

50. Fisher J, Astury J, Smith A. Adverse psychological impact of operative obstetric interventions: a prospective longitudinal study. Aust $N Z J$ Psychiatry. 1997;31:728-738.

51. Kendell RE, Mackenzie WE, West C, McGuire RJ, Cox JL. Dayto-day mood changes after childbirth: further data. $B r J$ Psychiatry. 1984;145:620-625.

52. Levy V. The maternity blues in post-partum and post-operative women. Br J Psychiatry. 1987;151:368-372.

53. Stein A, Cooper PJ, Campbell EA. Social adversity and perinatal complications: Their relation with postnatal depression. $B M J$. 1989;29:1073-1074.

54. Curran D, Partridge M, Storey P. Affective Disorders in Psychological Medicine. An Introduction to Psychiatry. London, UK: Churchill Livingstone; 1986.

55. Gelder M, Gath D, Mayou R. Psychiatric aspects of obstetrics and gynaecology. In: Oxford Textbook of Psychiatry. Oxford, UK: Oxford University Press; 1989.

56. Patel V, Rodrigues M, DeSouza N. Gender, poverty, and postnatal depression: a study of mothers in Goa, India. Am J Psychiatry. 2002;159:43-47.

57. Lee DT, Yip AS, Leung TY, Chung TK. Identifying women at risk of postnatal depression: prospective longitudinal study. Hong Kong Med J. 2000;6:349-354.
58. Paradiso S, Tauro N, Ronco F. Study of the psychology of maternity in women in puerperium. Minerva Med. 1986;77:51-52.

59. Dennis C, McQueen K. The relationship between infant-feeding outcomes and postpartum depression: a quantitative systematic review. Pediatrics. 2009;123:736-751.

60. Hatton DC, Harrison-Hohner J, Coste S, Dorato V, Curet LB, McCarron DA. Symptoms of postpartum depression and breastfeeding. J Hum Lact. 2005;21:444-454.

61. Yonkers KA, Ramin SM, Rush AJ, et al. Onset and persistence of postpartum depression in an inner-city maternal health clinic system. Am J Psychiatry. 2001;158:1856-1863.

62. Sherman C. Breast-feeding may halve the risk of postpartum depression. OB/GYN News July 15, 2002.

63. Bloch M, Schmidt PJ, Danaceau M, Murphy J, Nieman L, Rubinow DR. Effects of gonadal steroids in women with a history of postpartum depression. Am J Psychiatry. 2000;157:924-930.

64. Halbreich U. Postpartum disorders: multiple interacting underlying mechanisms and risk factors. J Affect Disord. 2005;88:1-7.

65. Harris B, Othman S, Davies JA, et al. Association between postpartum thyroid dysfunction and thyroid antibodies and depression. BMJ. 1992;305:152-156.

66. Gjerdingen DK, Yawn BP. Postpartum depression screening: importance, methods, barriers, and recommendations for practice. J Am Board Fam Med. 2007;20:280-288.

67. Ahokas A, Aito M, Turtiainen S. Association between oestradiol and puerperal psychosis. Acta Psychiatr Scand. 2000;101:167-170.

68. Pedersen CA, Stern RA, Senger MA, Bowes WA, Mason GA. Thyroid and adrenal measures during late pregnancy and the puerperium in women who become dysphoric postpartum. J Affect Disord. 1993;29:201-211.
Neuropsychiatric Disease and Treatment

\section{Publish your work in this journal}

Neuropsychiatric Disease and Treatment is an international, peerreviewed journal of clinical therapeutics and pharmacology focusing on concise rapid reporting of clinical or pre-clinical studies on a range of neuropsychiatric and neurological disorders. This journal is indexed on PubMed Central, the 'PsycINFO' database and CAS.

\section{Dovepress}

The manuscript management system is completely online and includes a very quick and fair peer-review system, which is all easy to use. Visit http://www.dovepress.com/testimonials.php to read real quotes from published authors. 